\title{
Carnosic acid and fisetin combination therapy enhances inhibition of lung cancer through apoptosis induction
}

\author{
BIN SHI $^{1}$, LI-FANG WANG ${ }^{1}$, WEN-SHU MENG $^{1}$, LIANG CHEN $^{2}$ and ZI-LI MENG ${ }^{2}$ \\ ${ }^{1}$ Department of Respiration, Suqian People's Hospital, Xuzhou Medical University, Suqian, Jiangsu 223800; \\ ${ }^{2}$ Department of Respiration, Huai'an First People's Hospital, Nanjing Medical University, Huai'an, Jiangsu 223300, P.R. China
}

Received November 14, 2016; Accepted January 9, 2017

DOI: $10.3892 /$ ijo.2017.3970

\begin{abstract}
Carnosic acid is a phenolic diterpene with antiinflammation, anticancer, anti-bacterial, anti-diabetic, as well as neuroprotective properties, which is generated by many species from Lamiaceae family. Fisetin (3,3',4',7-tetrahydroxyflavone), a naturally flavonoid is abundantly produced in different vegetables and fruits. Fisetin has been reported to have various positive biological effects, including anti-proliferative, anticancer, anti-oxidative and neuroprotective effects. Lung cancer is reported as the most common neoplasm in human world-wide. In the present study, the possible benefits of carnosic acid combined with fisetin on lung cancer in vitro and in vivo was explored. Carnosic acid and fisetin combination led to apoptosis in lung cancer cells. Caspase-3 signaling pathway was promoted in carnosic acid and fisetin co-treatment, which was accompanied by anti-apoptotic proteins of Bcl-2 and Bcl-xl decreasing and pro-apoptotic signals of Bax and Bad increasing. The death receptor (DR) of tumor necrosis factor-related apoptosis-inducing ligand (TRAIL) was enhanced in carnosic acid and fisetin combined treatment. Furthermore, the mouse xenograft model in vivo suggested that carnosic acid and fisetin combined treatment inhibited lung cancer growth in comparison to the carnosic acid or fisetin monotherapy. This study supplies a novel therapy to induce apoptosis to inhibit lung cancer through caspase- 3 activation.
\end{abstract}

\section{Introduction}

Lung cancer is known as one of the most common human cancers across the world (1). Lung cancer is a disease due to

Correspondence to: Dr Zi-Li Meng, Department of Respiration, Huai'an First People's Hospital, Nanjing Medical University, 6 Beijing Road West, Huai'an, Jiangsu 223300, P.R. China

E-mail: mengziliha@qq.com

Dr Bin Shi, Department of Respiration, Suqian People's Hospital, Xuzhou Medical University, Suqian, Jiangsu 223800, P.R. China E-mail: shibin998@126.com

Key words: carnosic acid, fisetin, lung cancer, caspase-3, apoptosis multiple factors (2). Among all lung cancers, the non-small cell lung cancer (NSCLC) accounts for approximately $80 \%$ (3). Despite continuous advances in treatments, lung cancer remains the main reason for cancer-related deaths (4). Thus, it is important to understand the molecular mechanisms and to find effective therapeutic strategies.

In the last several decades, finding the efficacy of various natural compounds against different human metabolic diseases have increased $(5,6)$. Compounds from many plants belonging to different groups, including alkaloids, polyphenols and flavonoids evaluated for their role in cancer-prevention, which have yielded promising data, thus, supplying a potential therapeutic strategy against deadly diseases (7). Carnosic acid (Fig. 1A) is known as a natural benzenediol abietane diterpene detected in rosemary and common sage (8). Carnosic acid is used as a preservative or antioxidant in food and non-food products, including toothpaste, mouthwash and chewing gum (9). Presently, carnosic acid has been suggested to possess some antitumor properties in mammary tumors, colonic cancer, as well as skin tumors via regulation of cell growth and apoptosis.

In addition, the flavonol fisetin (3,3',4',7-tetrahydroxyflavone) (Fig. 1B), in many kinds of fruits and vegetables such as grape, strawberries, apple, persimmon, onion and cucumber, was suggested to possess anti-oxidant, anti-microbial, anti-inflammatory and significantly anti-carcinogenic activity when studied in various animal model systems and cell cultures. Fisetin is a hydrophobic compound, penetrating cell membranes in cells to perform its effects $(10,11)$. For example, it is claimed to be an orally active neuroprotective and memory-enhancing molecule (12). Additionally, fisetin could induce apoptosis in cervical and breast cancer cells $(13,14)$. Furthermore, fisetin induced cell apoptotic death in human hepatocellular carcinoma via p21 signaling pathway regulation (15). Thus, we considered that fisetin might have effective role in human gastric cancer progression inhibition.

The present study aimed to calculate the potential benefit and value of carnosic acid and fisetin in combination for lung cancer treatment and to explore the possible molecular mechanism by which the combinational therapy acts in modulating lung cancer. To the best of our knowledge, this is the first time that carnosic acid combined with fisetin is used to prevent lung cancer in vitro and in vivo studies, which 
might provide new therapeutic strategy for lung cancer treatment.

\section{Materials and methods}

Cells and culture. Human lung caner cell lines, HCC827 and H358 and human normal lung cells MRC-5 were purchased from the American Type Culture Collection (ATCC; Manassas, VA, USA). HCC827 and H358 cells were routinely cultured in RPMI-1640 medium (Gibco, Waltham, MA, USA), containing $10 \%$ fetal bovine serum (FBS; Gibco) and 1\% penicillin/streptomycin. MRC-5 was cultured in Dulbecco's modified Eagle's medium (DMEM; Gibco) supplemented with $10 \% \mathrm{FBS}, 100 \mathrm{U} / \mathrm{ml}$ penicillin and $100 \mu \mathrm{g} / \mathrm{ml}$ streptomycin. All cells were cultured in a humidified atmosphere with $5 \%$ $\mathrm{CO}_{2}$ and $95 \%$ humidity at $37^{\circ} \mathrm{C}$ in an incubator. Fisetin and carnosic acid ( $>98 \%$ purity), used for the treatment of lung cancer, were purchased from Hangzhou DayangChem, Co., Ltd. (Hangzhou, China), which was dissolved in dimethyl sulfoxide (DMSO) and stored at $-20^{\circ} \mathrm{C}$, and then diluted in medium for experimental treatment. The final DMSO concentration in the present study is no more than $0.1 \%(\mathrm{v} / \mathrm{v})$ in each treatment.

MTT analysis. Cells $\left(5 \times 10^{3}\right)$ were seeded into a 96-well plate/well. Carnosic acid $(0-40 \mu \mathrm{M})$, fisetin $(0-40 \mu \mathrm{M})$, or the combination of both was added to the medium after $24 \mathrm{~h}$. The cells were then incubated at $37^{\circ} \mathrm{C}$ for $24 \mathrm{~h}$, and the cell viability was detected by the colorimetric MTT assay at $570 \mathrm{~nm}$ (16).

Colony-forming assays. Lung cancer cells (500)/well in $60-\mathrm{mm}$ plates were cultured in 10\% FBS RPMI-1640. Cells were treated with fisetin and carnosic acid of the indicated concentrations for $24 \mathrm{~h}$. After another 7 days of incubation, the cell colonies were washed twice with phosphate-buffered saline (PBS), fixed with $4 \%$ paraformaldehyde for $15 \mathrm{~min}$ and then stained by Gimsa for $30 \mathrm{~min}$. All the clones with over 50 cells were evaluated. Clone forming efficiency for cells was calculated based on colonies/number of inoculated cells x $100 \%$ (17).

Cell migration assays. Lung cancer cells were seeded into the upper chamber of a Transwell insert pre-coated with $5 \mu \mathrm{g} / \mathrm{ml}$ fibronectin for migration or a $\mathrm{BD}^{\text {TM }}$ Matrigel invasion chamber. Medium with $10 \%$ serum was put in the lower chamber as a chemo-attractant, and cells were then incubated for $4 \mathrm{~h}$ for migration. Non-migratory cells were removed from the upper chamber by scraping with a cotton bud. The cells on the lower insert surface were stained with Diff-Quick. Cells were evaluated as the number of cells observed in five different microscope fields of three independent inserts (18).

Scratch wound-healing analysis. The lung cancer cells used in this study were seeded and grown on a 6-well plate overnight. The monolayers of lung cancer cells were wounded with a pipette tip. Cells were then washed with PBS to discard cellular debris and subjected to migration for $24 \mathrm{~h}$. Representative images were taken at 0 and $24 \mathrm{~h}$ after the wounding through an inverted microscope (19).
Caspase-3 and -9 analysis. Caspase-3 and -9 activities were measured by colorimetric activity assay kits (Clontech Laboratories, Inc., Mountain View, CA, USA) following the manufacturer's instructions. The analysis is according to the chromogenic substrates cleavage, DEVD-pNA by caspase- 3 and LEHD-pNA by caspase-9, respectively. Cells were dissolved in cold lysis buffer for $10 \mathrm{~min}$ and centrifuged at $10,000 \mathrm{x} \mathrm{g}$ for $5 \mathrm{~min}$. Then, solution of caspase substrate containing specific peptide substrate was added to the supernatant and grown at $37^{\circ} \mathrm{C}$ for $2 \mathrm{~h}$ before ELISA reader assay at $405 \mathrm{~nm}$.

DNA staining analysis. Hoechst 33258 stain for DAPI staining analysis was performed for morphological calculation of the nuclei. Lung cancer cells were incubated with carnosic acid and fisetin and the two combinations for $24 \mathrm{~h}$. HCC827 and H358 cells were washed with ice-cold PBS three times in 6-well plate and then stained with $0.5 \mathrm{ml}$ Hoechst 33258 solution for $10 \mathrm{~min}$ at $37^{\circ} \mathrm{C}$ avoiding light. Then, the cancer cells were washed with ice-cold PBS three times in the plate. The cells were observed with an inverted fluorescence microscope (Olympus Corp., Tokyo, Japan) (20).

Apoptosis assays. Apoptosis assay of samples was also determined by terminal deoxynucleotidyl transferase-mediated dUTP nick end labeling (TUNEL) using an In Situ Cell Death Detection kit, Fluorescein (Roche Applied Science, South San Francisco, CA, USA) according to the manufacturer's protocol. The number of TUNEL-positive cells was counted under a fluorescence microscope. The percentages of apoptotic cells were calculated from the ratio of apoptotic cells to total cells counted. Tissue sections were counter-stained with hematoxylin. Sections were mounted and observed under a light microscope. The experiment was performed independently three times.

Western blot analysis. The lung cancer cells and tumor tissue samples from mice were homogenized into $10 \%$ (wt/vol) hypotonic buffer (25 mM Tris-HCl, pH 8.0, 1 mM EDTA, $5 \mu \mathrm{g} / \mathrm{ml}$ leupeptin, $1 \mathrm{mM}$ Pefabloc SC, $50 \mu \mathrm{g} / \mathrm{ml}$ aprotinin, $5 \mu \mathrm{g} / \mathrm{ml}$ soybean trypsin inhibitor and $4 \mathrm{mM}$ benzamidine) to yield a homogenate. Then, the final supernatants were obtained by centrifugation at $12,000 \mathrm{rpm}$ for $15 \mathrm{~min}$. Protein concentration was determined by BCA protein assay kit (Thermo Fisher Scientific, Waltham, MA, USA) with bovine serum albumin as a standard. The total protein extract was used for western blot analysis. Equal amounts of total protein of tissues were subjected to $10 \%$ SDS-PAGE followed by immunoblotting using the following primary polyclonal antibodies $(1: 1,000)$ : rabbit anti-GAPDH, Bcl-xl, caspase-9, caspase-8, caspase-3, Bcl-2, Bad and Bax. Immunoreactive bands were visualized by ECL Immunoblot Detection system (Pierce Biotechnology, Inc., Rockford, IL, USA) and exposed to Kodak (Eastman Kodak Company, Rochester, NY, USA) X-ray film. Each protein expression level was defined as grey value (Version 1.4.2b, Mac OS X, ImageJ; National Institutes of Health, Bethesda, MD, USA) and standardized to housekeeping genes (GAPDH) and expressed as a fold of control.

$R T$-qPCR assays. qPCR analysis, was performed as previously described $(16,21)$. Fold induction values were calculated using 
Table I. Primer sequences of RT-PCR test.

\begin{tabular}{lll}
\hline Gene & \multicolumn{1}{c}{ Forward primers $\left(5^{\prime}-3^{\prime}\right)$} & \multicolumn{1}{c}{ Reverse primers $\left(5^{\prime}-3^{\prime}\right)$} \\
\hline DR4 & TAGGTGAGGTGGAGCTCAGATG & TGCAACAGCGAAGACCTATTA \\
DR5 & TATGGGAGCAACCGCTATA & CGCGAACACAATGGCTATAA \\
TRAIL & GAAACACGGTGACCACACCC & CTCACAACGCTGCGGCGA \\
Bcl-xl & ACAAACACCGCTGGCCA & GCAGCATTACACAAACCAAGC \\
FADD & ACAACGCTTCCAGCACC & CCCGTTATGCGAAACCA \\
Bad & TCACCAACGTTCGTCGT & CATTGTCGTTGCAAGTATG \\
Bax & AGCAAGACAAGGATGCTCG & CAGCGTTCCATGTCAGTTATGTG \\
Bcl-2 & GAGGCCAAGACAGGTATAC & GCGTGGCAATTTAAGTTGTG \\
GAPDH & CATTCAAGACCGGACAGAGG & ACATACTCAGCACAGCATCACC \\
\hline
\end{tabular}

the to $2^{-\Delta \Delta \mathrm{Cq}}$ method, where $\Delta \mathrm{Cq}$ represents the differences in cycle threshold number between the target gene and GAPDH, and $\Delta \Delta \mathrm{Cq}$ represents the relative change in the differences between the control and the treatment groups. The primers used in the study are shown in Table I.

Athymic nude mouse model. Eight-week-old athymic nude mice were purchased from the Animal Center of Nanjing Medical University (Nanjing, China) and kept in a $25 \pm 2{ }^{\circ} \mathrm{C}$ temperature and $50 \pm 10 \%$ humidity-controlled environment with a standard $12 \mathrm{~h}$ light/dark cycle with food and water in cages under germ-free conditions. All processes were in accordance with the Institutional Animal Care and Use Committee of Huai'an First People's Hospital, Nanjing Medical University. Briefly, 5x10 ${ }^{5} \mathrm{HCC} 827$ and H358 cells were subcutaneously injected into the dorsal flanks of nude mice. Tumor volume was measured by calculating the two maximum perpendicular tumor diameters every three days. The tumor-bearing nude mice were randomly divided into 4 groups: i) control; ii) CA (30 mg/kg); iii) FE (20 mg/kg); and iv) $\mathrm{CA}$ and FE combination every two day for 35 days. Carnosic acid and fisetin were dissolved in DMSO and then diluted in distilled water. The mice were administered with CA and FE orally. The control group was given DMSO diluted in water $(0.5 \% \mathrm{v} / \mathrm{v})$. The body weight was measured twice a week. The tumor volume was evaluated by a formula $1 / 2(\mathrm{~L} 1 \times \mathrm{L} 2 \times \mathrm{H})$ where $\mathrm{L} 1$ is the long diameter, L2 is the short diameter and $\mathrm{H}$ is the height of tumor. At the end of the present study, the mice were sacrificed. The tumor tissue samples were removed for molecular mechanism research and immunohistochemical analysis.

Immunohistochemical (IHC) assays. The tissues in each group were fixed with $10 \%$ buffered formalin, imbedded in paraffin and sliced into $4-5 \mu \mathrm{m}$ thick sections. Tumor tissues also were subjected to immunohistochemical (IHC) staining for the analysis of p53 expression. The sections were stained with $\alpha$-SMA, collagen type I, collagen type II and MMP-9. All the histological examinations were carried out according to the standard procedures previously reported $(17,22)$.

Statistical analysis. Data were expressed as mean \pm standard error of the mean (SEM). Statistical analyses were performed using GraphPad Prism (version 6.0; GraphPad software) by ANOVA with Dunnet's least significant difference post-hoc tests. A $\mathrm{P}<0.05$ was considered statistically significant.

\section{Results}

Carnosic acid and fisetin combination significantly suppresses lung cancer cell proliferation. Before confirming the role of carnosic acid with fisetin combination $(\mathrm{CA} / \mathrm{FE})$ in lung cancer, the possible cytotoxicity of CA, FE and CA/FE towards lung cancer tumor cells and normal human lung epithelia cells was explored. As shown in Fig. 1C and D, at the concentrations of $15 \mu \mathrm{M}$ or lower, CA showed no significant anticancer role in lung cancer cells of HCC827 and H358. Over 20 and $15 \mu \mathrm{M}$, CA exhibited remarkable effects on suppressing HCC827 and $\mathrm{H} 358$ cells, respectively, suggesting that CA, to some degree, possesses inhibitory role in controlling lung cancer cells, especially combined with FE. However, no significant cytotoxicity was observed in normal lung epithelia cells of MRC-5 even at the highest concentration of $40 \mu \mathrm{M}$ (Fig. 1E). Of note, after combination with $\mathrm{FE}$, huge anti-proliferation ability of $\mathrm{CA}$ and $\mathrm{FE}$ was observed. Significant difference was found at the combination of CA at $10 \mu \mathrm{M}$ with $20 \mu \mathrm{M} \mathrm{FE}$ and $5 \mu \mathrm{M}$ CA with $20 \mu \mathrm{M}$ FE in HCC827 and H358 cancer cells, respectively, illustrating that $\mathrm{CA}$ combined with $\mathrm{FE}$ displayed effective antitumor role in lung cancer cells. Then, $20 \mu \mathrm{M}$ CA was used combined with different concentrations of FE to investigate the monotherapy of FE and its combination with CA on lung cancer. As seen in Fig. 1F and G, FE alone could also reduce lung cancer cells viability in a dose-dependent manner. In addition, significant difference was found with up to 15 or $20 \mu \mathrm{M}$ in HCC827 and $\mathrm{H} 358$ cells, respectively. Compared to $\mathrm{FE}$ alone, CA/FE combination showed strong antitumor effects on HCC827 and H358 proliferation. On the contrary, no cytotoxicity was observed in MRC-5 cells with the increase of CA treatment (Fig. 1H). The data suggest that $\mathrm{CA} / \mathrm{FE}$ possesses huge antitumor role in lung cancer cell proliferation without causing cytotoxicity in normal cells. In the present study, the concentrations of CA $(20 \mu \mathrm{M})$ and $\mathrm{FE}(20 \mu \mathrm{M})$ were used for combinational therapy in the following investigation.

Carnosic acid and fisetin combination therapy inhibits lung cancer cell proliferation. In this regard, we attempted to 
A<smiles>CC(C)c1cc2c(c(O)c1O)C13CCCC(C)(CC1CC2)C3C(=O)O</smiles>
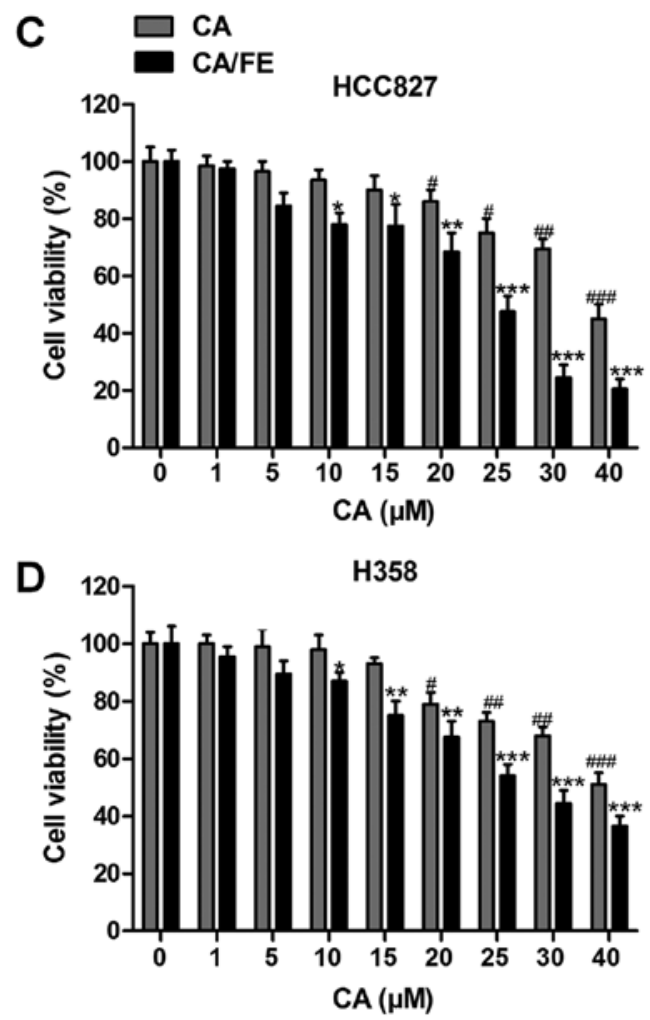

E

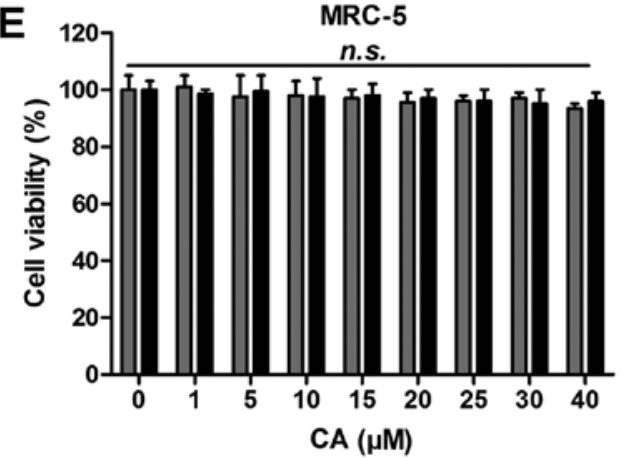

B<smiles>O=C1CC(c2ccc(O)c(O)c2)Oc2cc(O)ccc21</smiles>

F $\square$ FE
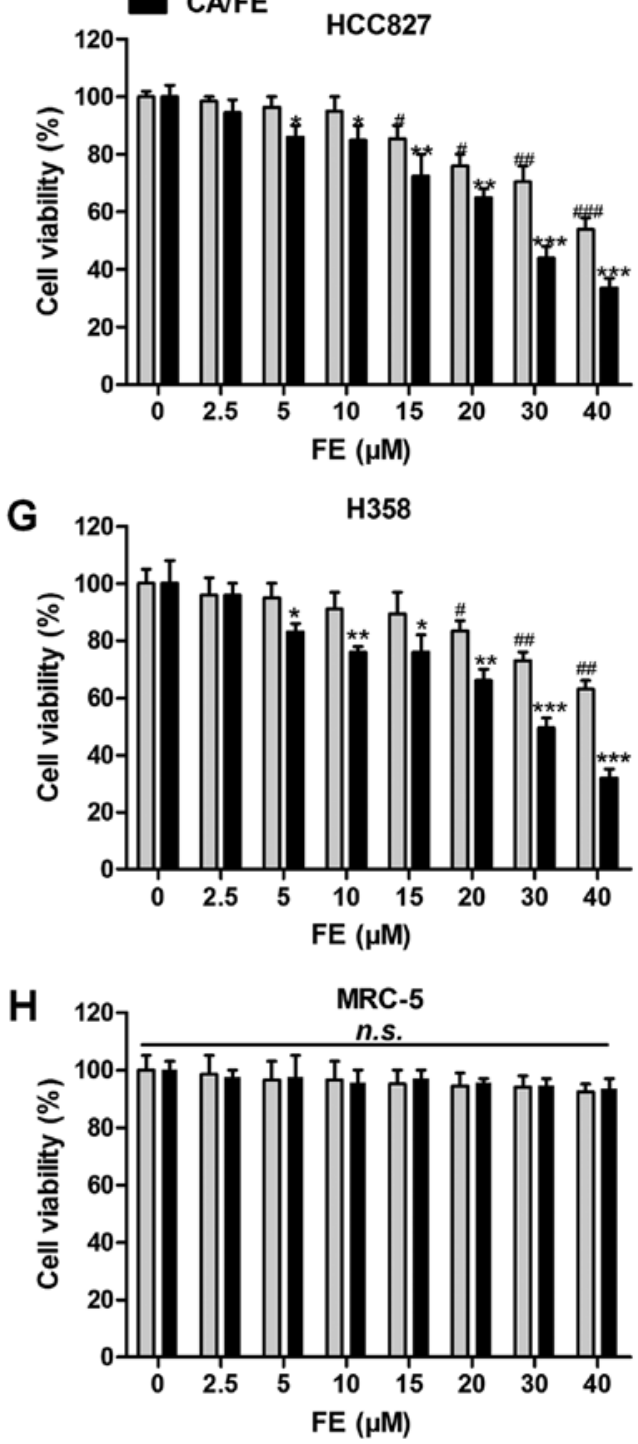

Figure 1. Effects of carnosic acid and fisetin significantly suppress lung cancer cell proliferation. The chemical structure of (A) carnosic acid and (B) fisetin is displayed. Left column, MTT analysis of (C) HCC827, (D) H358 and (E) MRC-5 cells treated with different concentrations (0, 1, 5, 10, 15, 20, 25, 30 and $40 \mu \mathrm{M})$ of CA in the presence or absence of FE $(20 \mu \mathrm{M})$ for $24 \mathrm{~h}$. Right column, MTT analysis of (F) HCC827, (G) H358 and (H) MRC-5 cells treated with different concentrations $(0,2.5,5,10,15,20,30$ and $40 \mu \mathrm{M})$ of FE with or without $\mathrm{CA}(20 \mu \mathrm{M})$ for $24 \mathrm{~h}$. Values are means $\pm \mathrm{SEM} .{ }^{*} \mathrm{P}<0.05,{ }^{* *} \mathrm{P}<0.01$ and ${ }^{* * * *} \mathrm{P}<0.001$ vs. Con group of $\mathrm{CA} / \mathrm{FE}$ combination; ${ }^{\#} \mathrm{P}<0.05,{ }^{\# \#} \mathrm{P}<0.01$ and ${ }^{\# \# \#} \mathrm{P}<0.001$ vs. Con group of CA or FE monotherapy. n.s., no significance; CA, carnosic acid; FE, fisetin.

investigate the effects of $\mathrm{CA} / \mathrm{FE}$ treatment on lung cancer cells proliferation and migration. Whether the treatment of $\mathrm{CA} / \mathrm{FE}$ influenced the clonogenic growth of $\mathrm{HCC} 827$ and H358, colony-forming analysis was assessed. Our colony formation assays showed that $\mathrm{CA}$ and $\mathrm{FE}$ monotherapy significantly reduced the colony number of cancer cells compared to the control ones. Notably, combination of CA/FE markedly decreased the clonogenic growth of lung cancer cells of
HCC827 (19.36\%) and H358 (25.87\%), which was comparable to $\mathrm{CA}$ and $\mathrm{FE}$ alone in HCC827 (40.29 and 38.95\%) and $\mathrm{H} 358$ (71.23 and 56.37\%) cells (Fig. 2A and B). In the presence of $\mathrm{CA}$ and FE single therapy, the number of migrated cells of HCC 827 and H358 was decreased. However, combination of $\mathrm{CA} / \mathrm{FE}$ noticeably resulted in a decreased number of migrated cancer cells of HCC827 (10.58\%) and H358 (11.46\%) (Fig. 2C and D). Next, the relative wound width of HCC827 and H358 

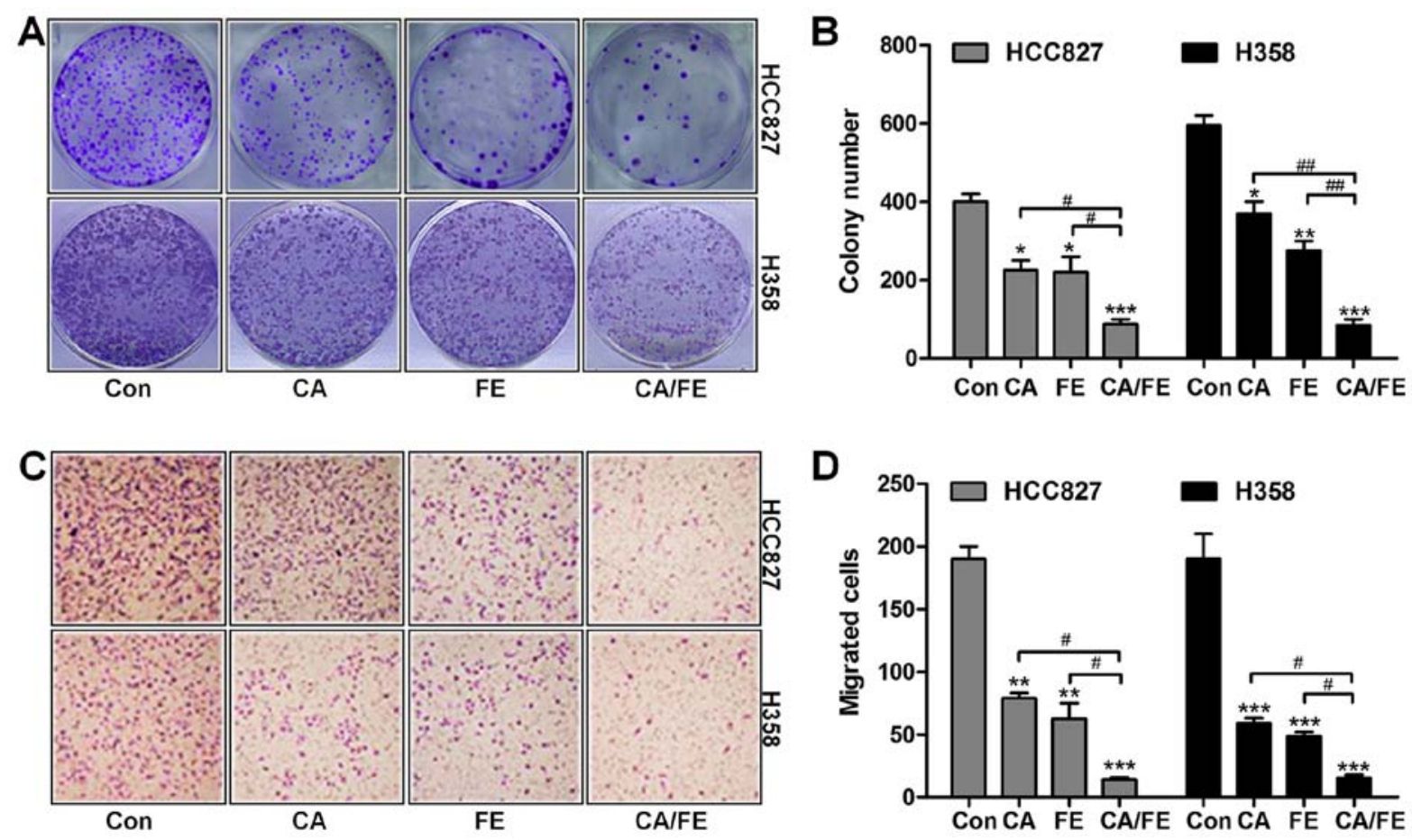

Figure 2. Carnosic acid and fisetin combination therapy inhibits lung cancer cell proliferation. (A) Representative images exhibiting cellular colonies of HCC827 and H358 after different treatments. (B) The quantification of colony-forming results. (C) Representative images showing the migrated lung cancer cells under different treatment conditions. (D) The quantification of lung cancer cells migration after different treatments for $24 \mathrm{~h}$. Values are means $\pm \mathrm{SEM}$. ${ }^{*} \mathrm{P}<0.05,{ }^{* *} \mathrm{P}<0.01$ and ${ }^{* * * *} \mathrm{P}<0.001$ vs. Con group; ${ }^{\#} \mathrm{P}<0.05,{ }^{\# \#} \mathrm{P}<0.01$.

A

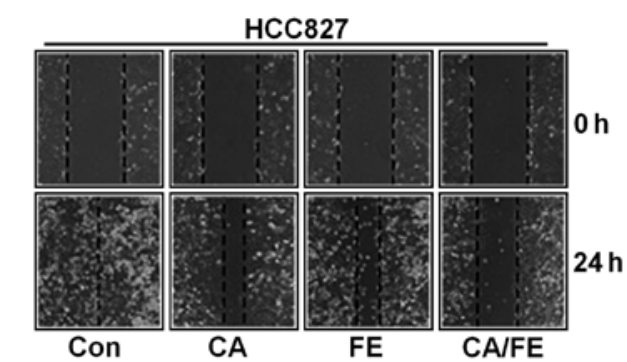

C

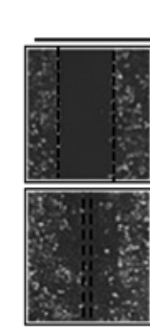

Con

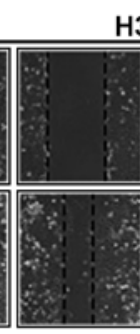

CA
358

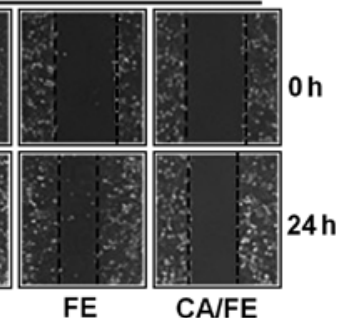

B

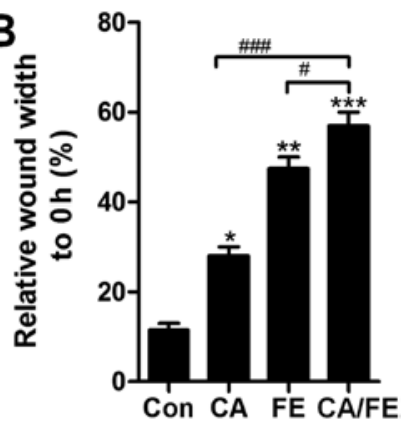

Dr

Figure 3. Carnosic acid and fisetin combinational therapy suppresses lung cancer cell growth. (A) Representative photomicrographs displaying the HCC827 cells migrated across the scratch wound after different treatments. (B) The quantification of wound-triggered cell motility in HCC 827 cells. (C) The representative photomicrographs displaying the $\mathrm{H} 358$ cells migrated across the scratch wound after different treatments. (D) The quantification of wound-triggered cell motility in $\mathrm{H} 358$ cells is shown. Values are means $\pm \mathrm{SEM}$. ${ }^{*} \mathrm{P}<0.05,{ }^{* *} \mathrm{P}<0.01$ and ${ }^{* * *} \mathrm{P}<0.001$ vs. Con group; ${ }^{\#} \mathrm{P}<0.05,{ }^{\# \#} \mathrm{P}<0.01$ and ${ }^{\# \# \#} \mathrm{P}<0.001$.

cells were detected after different treatments. Fig. 3A and B show that, CA and FE monotherapy increased in controlling the wound width of HCC827 (27.83 and 46.98\%), which was also observed in H358 cells (46.59 and 72.36\%), accompanying with remarkable difference compared to the control (Fig. 3C and D). Also, in the presence of CA and FE, the wound width to $0 \mathrm{~h}$ was found to be the highest in HCC827 (58.69\%) and H358 (93.18\%) cells, and considerable difference was observed 
A

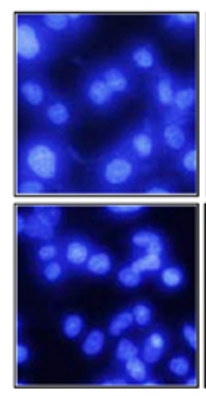

Con

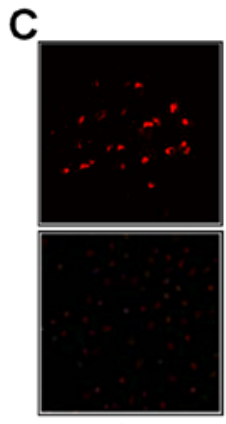

Con

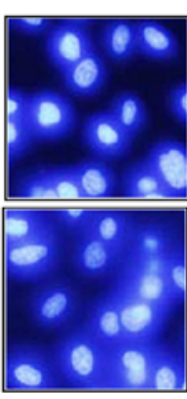

CA

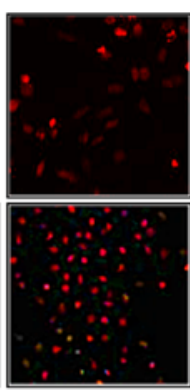

CA

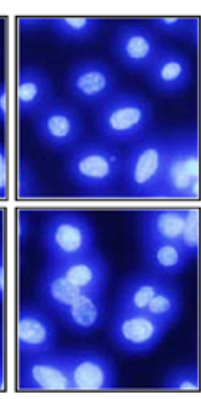

FE

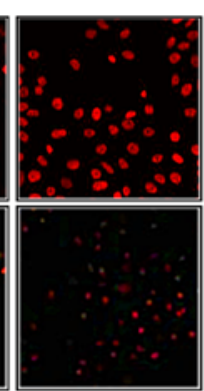

FE

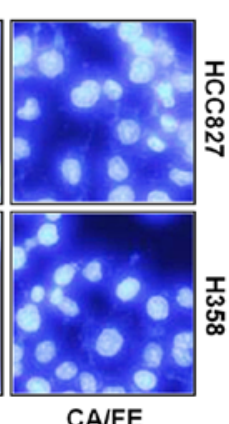

CA/FE

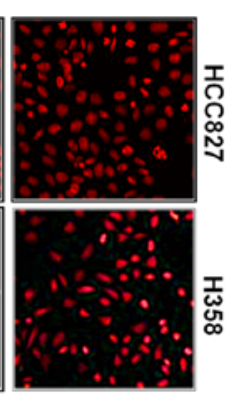

CA/FE

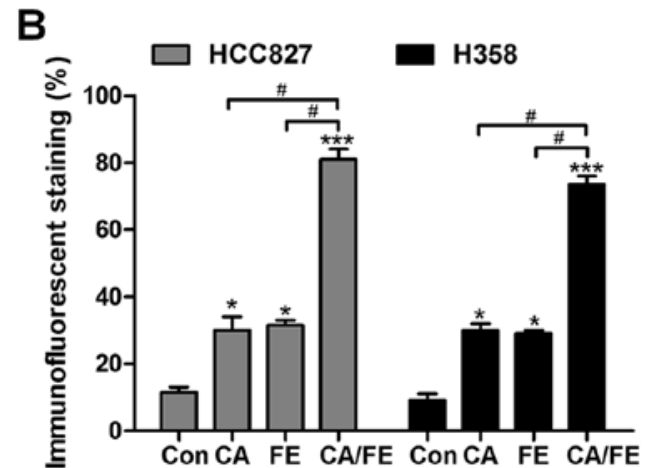

D

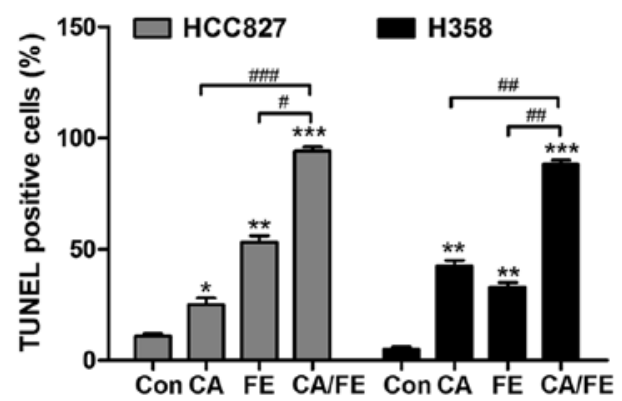

Figure 4. Carnosic acid and fisetin co-treatment significantly induce apoptosis of lung cancer cells. (A) The morphological changes of nuclei during CA-, FE-, CA/FE-induced apoptosis in HCC827 and H358 cells determined by Hoechst 33258 staining. (B) The quantification of Hoechst 33258 results is exhibited in HC827 and H358 cells. (C) The representative images of TUNEL assays in HCC827 and H358 cells under different treatments. (D) The quantification of TUNEL analysis for apoptosis results in $\mathrm{HCC} 827$ and $\mathrm{H} 358$ cancer cells is shown. Values are means $\pm \mathrm{SEM}$. ${ }^{*} \mathrm{P}<0.05{ }^{* *} \mathrm{P}<0.01$ and ${ }^{* * *} \mathrm{P}<0.001$ vs. Con group; ${ }^{\#} \mathrm{P}<0.05,{ }^{\# \#} \mathrm{P}<0.01$ and ${ }^{\# \#} \mathrm{P}<0.001$.

in comparison to the CA and FE single treatment. The results illustrate the capability of CA/FE to suppress lung cancer cells proliferation and migration which is apparently stronger than the effect of CA and FE separately in the present experiments.

Carnosic acid and fisetin co-treatment significantly induces apoptosis of lung cancer cells. We assessed whether CA/FE co-treatment has any effects on apoptosis, contributing to lung cancer cells proliferation suppression and death. As shown in Fig. 4A and B, in comparison to the control group, CA, FE and $\mathrm{CA} / \mathrm{FE}$ treatments led to shrunken cancer cell nuclei and most cell nuclei were apparently condensed and brightly stained. Nuclear condensation has been considered as a typical change of morphology for cells experiencing apoptosis (23). TUNEL assays indicated that $\mathrm{CA}$ and FE single treatment caused higher number of apoptotic cells in comparison to the control ones, which was further enhanced for $\mathrm{CA} / \mathrm{FE}$ combination in HCC827 (92.35\%) and H358 (88.27\%) cells. Of note, significant difference was observed between the CA/FE and CA and FE alone groups both in HCC827 (CA, 24.86\%; FE, 55.73\%) and $\mathrm{H} 358$ cells (CA, 41.08\%; FE, 34.64\%) (Fig. 4C and D). The results above suggest the ability of $\mathrm{CA} / \mathrm{FE}$ to trigger $\mathrm{HCC} 827$ and $\mathrm{H} 358$ cell apoptosis is markedly stronger than $\mathrm{CA}$ and $\mathrm{FE}$ single therapy.

Carnosic acid and fisetin induce apoptosis in lung cancer cells through caspase-3 activation. The results mentioned above indicated that apoptosis could be induced for CA, FE especially the CA/FE combination. Hence, the molecular mechanism was explored. Caspase-8 activation results in down-stream signals of caspase- 9 and caspase- 3 activity (24). Next, the caspase activation of cancer cells after $\mathrm{CA}, \mathrm{FE}$ and $\mathrm{CA} / \mathrm{FE}$ treatment were determined through western blot analysis. As shown in Fig. 5A, CA and FE markedly induced high cleavage of caspase-8, leading to caspase- 9 activation. Consequently, caspase- 3 was activated and apoptosis was induced. Significantly, CA/FE combination resulted in an obvious more intensive caspase- 8 (Fig. 5B), caspase-9 (Fig. 5C) and caspase-3 (Fig. 5D) cleavage in lung cancer cells of $\mathrm{HCC} 827$. Moreover, in H358 cells, cleaved caspase-8 (Fig. 5E and F), caspase-9 (Fig. 5E and G) and caspase-3 (Fig. 5E and H) were markedly elevated in $\mathrm{CA} / \mathrm{FE}$ group compared to the CA and $\mathrm{FE}$ single treatment.

In order to further confirm the role of CA and FE in caspases activity, caspase- 3 and caspase- 9 inhibitors were used in the present study. Fig. 6A, shows that caspase-3 activity was highly elevated in the $\mathrm{CA} / \mathrm{FE}$ combination group with significant difference compared to the CA and FE single therapy. Caspase-3 inhibitor usage abolished caspase-3 activity triggered by CA/FE. Also, CA/FE-induced high caspase- 9 activation was also suppressed due to caspase-9 inhibitor treatment in HCC827 cells (Fig. 6B). In addition, H358 cells after CA/FE co-treatment showed markedly higher activity of caspase-3 and caspase-9, which was comparable to the monotherapy-treated groups. Of note, caspase- 3 and caspase- 9 inhibitors pre-treatment noticeably failed to induce caspase activation (Fig. 6C and D). The results above show that caspase signaling pathway activation is involved in CA/FE-induced 

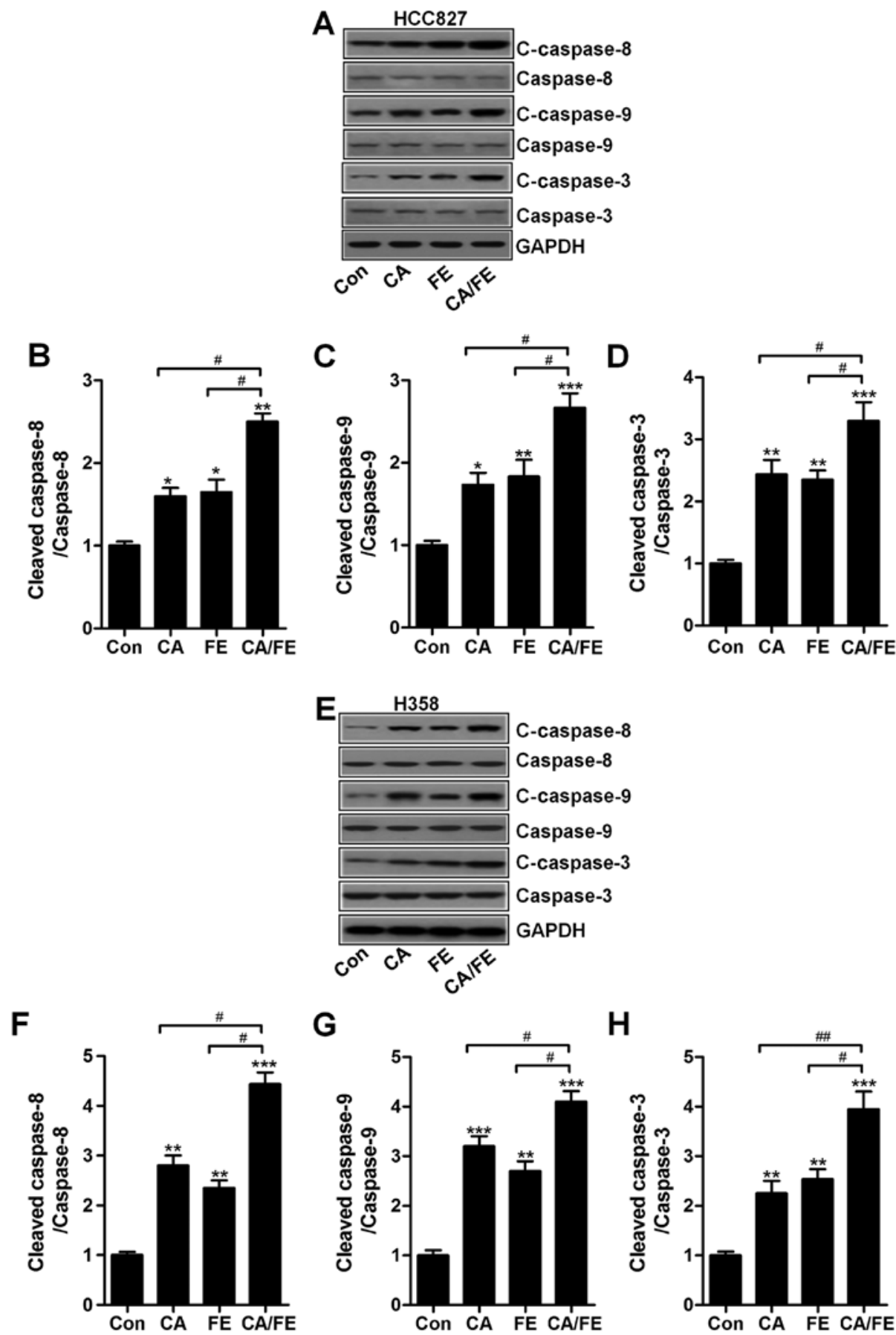

Figure 5. Combination of carnosic acid and fisetin induces apoptosis in lung cancer cells through caspase-3 activation. (A) HCC827 cells were given CA, FE or the combination of the two for $24 \mathrm{~h}$. Total protein was extracted and then subjected to immunoblot analysis for cleaved caspase-8, caspase-9 and caspase-3 detection. GAPDH was conducted as loading control. The quantification of cleaved (B) caspase-8, (C) caspase-9 and (D) caspase-3 is exhibited. (E) H358 cells were given CA, FE or the combination of CA/FE for $24 \mathrm{~h}$. Total protein was extracted and then subjected to immunoblot analysis for cleaved caspase- 8 , caspase- 9 and caspase- 3 detection. GAPDH was the loading control. The quantification of cleaved (F) caspase- $8,(\mathrm{G})$ caspase- 9 and $(\mathrm{H})$ caspase-3 is exhibited . Values are means \pm SEM. ${ }^{*} \mathrm{P}<0.05,{ }^{* *} \mathrm{P}<0.01$ and ${ }^{* * *} \mathrm{P}<0.001$ vs. Con group; ${ }^{*} \mathrm{P}<0.05,{ }^{\# \#} \mathrm{P}<0.01$.

apoptosis, which is a main molecular mechanism by which $\mathrm{CA} / \mathrm{FE}$ exhibits stronger antitumor effects.

Carnosic acid and fisetin combination-induced apoptosis is associated with mitochondrial pathway. Bcl-2 family members can be divided into the anti-apoptotic proteins, including Bcl-2 and Bcl-xl, and pro-apoptotic signals, such as Bax and $\mathrm{Bad}(25)$. We further investigated the role of $\mathrm{CA} / \mathrm{FE}$ combined therapy in the balance between the pro-apoptotic and anti- apoptotic members. The combinational treatment of CA/FE on $\mathrm{HCC} 827$ (Fig. 7A) significantly decreased Bcl-2 and Bcl-xl (Fig. 7C and D), while Bax (Fig. 7B and E) and Bad (Fig. 7B and $\mathrm{F}$ ) protein levels were markedly increased in NSCLC cells after the combined $\mathrm{H} 358$ cancer cells significantly decreased Bcl-2 (Fig. 7G and I) and Bcl-xl (Fig. 7G and J), while Bax (Fig. $7 \mathrm{H}$ and $\mathrm{K}$ ) and Bad (Fig. $7 \mathrm{H}$ and $\mathrm{L}$ ) protein levels were markedly increased in NSCLC cells after the combined treatment of CA/FE. 
A

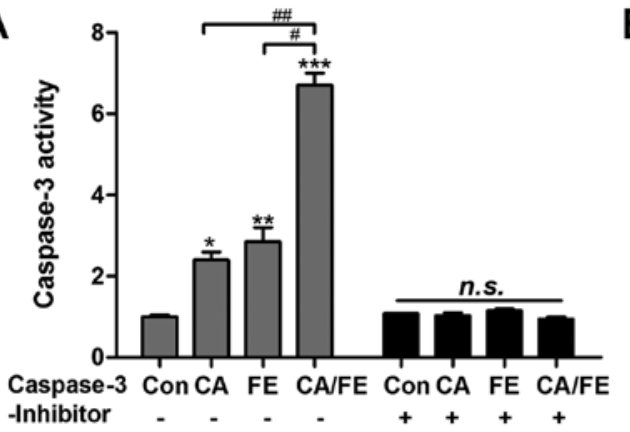

C

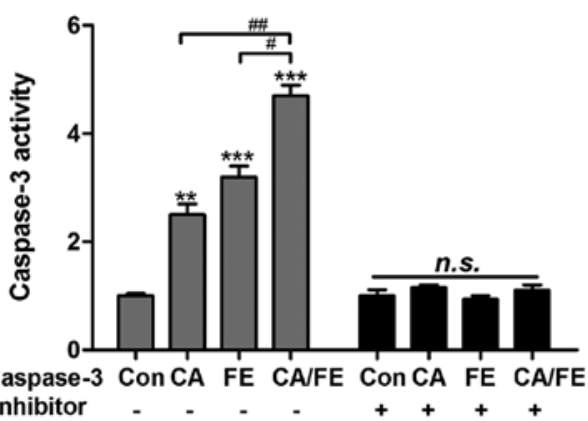

B

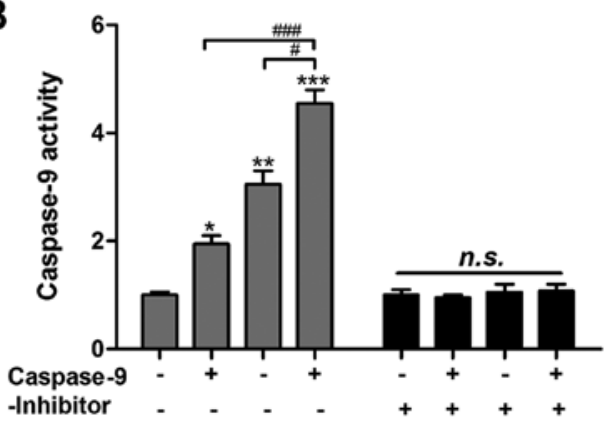

D

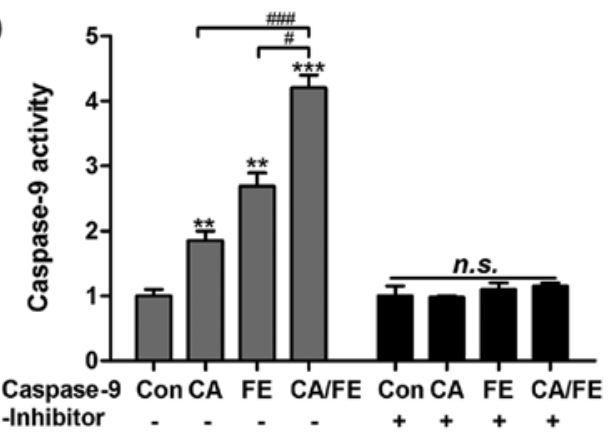

Figure 6. Carnosic acid and fisetin double therapy-induced apoptosis in lung cancer cells through caspase-3 activation can be reversed for caspase inhibitor use. (A) Caspase-3 activation was determined in HCC827 cells administered with CA and FE alone or the combination in the absence or presence of caspase-3 inhibitor for $24 \mathrm{~h}$. (B) Caspase-9 activation was determined in HCC827 cells administered with CA and FE alone or the combination in the absence or presence of caspase- 9 inhibitor for $24 \mathrm{~h}$. (C) Caspase- 3 activation was determined in $\mathrm{H} 358$ cells administered with CA and FE alone or the combination in the absence or presence of caspase-3 inhibitor for $24 \mathrm{~h}$. (D) Caspase- 9 activation was determined in $\mathrm{H} 358$ cells administered with CA and FE alone or the combination in the absence or presence of caspase-9 inhibitor for $24 \mathrm{~h}$. Values are means $\pm \mathrm{SEM}$. ${ }^{*} \mathrm{P}<0.05,{ }^{* *} \mathrm{P}<0.01$ and ${ }^{* * *} \mathrm{P}<0.001$ vs. Con group; ${ }^{\#} \mathrm{P}<0.05,{ }^{\# \#} \mathrm{P}<0.01$ and $\# \# \mathrm{P}<0.001$

The effects of carnosic acid and fisetin combination suppress lung cancer cells through TRAIL signaling pathway regulation. TRAIL can induce rapid apoptosis in various cancers (26). TRAIL-induced apoptosis relies on DRs, leading to the formation of death-inducing signaling complex. FADD, subsequently, is activated to improve caspase- 8 activity (27). In HCC 827 and $\mathrm{H} 358$ cancer cells under various conditions, RT-qPCR analysis was carried out to explore how TRAIL, DR4, DR5 and FADD altered after CA and FE single treatment, or CA/ FE co-treatment in HCC827 and $\mathrm{H} 358$ cells, respectively. The results showed that in HCC827 cells, TRAIL (Fig. 8A), DR4 (Fig. 8B), DR5 (Fig. 8C) and FADD (Fig. 8D) mRNA levels were significantly augmented by $\mathrm{CA}$ and FE monotherapy. Notably, co-treatment of CA/FE markedly stimulated TRAIL, DR4, DR5 and FADD levels, which was comparable to the single-treated groups. Furthermore, in H358 cells, TRAIL (Fig. 8E), DR4 (Fig. 8F), DR5 (Fig. 8G) and FADD (Fig. 8H) mRNA levels were apparently improved by CA and FE single therapy. Of note, co-treatment of CA/FE markedly stimulated TRAIL, DR4, DR5 and FADD levels, which was comparable to the $\mathrm{CA}$ and $\mathrm{FE}$ alone-treated groups. The results indicate that mitochondrial pathway is involved in CA/FE-induced apoptosis, which is associated with TRAIL/DRs signaling pathway.

Carnosic acid and fisetin combination suppresses tumor growth in lung cancer xenograft models in vivo. The present study indicated that CA/FE co-treatment was inhibitory in lung cancer cell proliferation in vitro. Hence, in order to further investigate the role of $\mathrm{CA}$ and $\mathrm{FE}$ monotherapy, and $\mathrm{CA} / \mathrm{FE}$ combined treatment on tumor growth, the athymic nude mice bearing the established $\mathrm{HCC} 827$ and $\mathrm{H} 358$ cells subcutaneous tumors in the presence of either $30 \mathrm{mg} / \mathrm{kg} \mathrm{CA}, 20 \mathrm{mg} / \mathrm{kg} \mathrm{FE}$ or the two combinations were assessed. CA and FE by themselves significantly reduced tumor volume (Fig. 9A and B) and tumor weight (Fig. 9C) compared to the control group. Notably, CA/FE combination showed stronger antitumor role in controlling the tumor volume and weight and marked difference was observed between the CA/FE and CA- and FE-alone groups. Additionally, no apparent difference of body weight was found between different groups in HCC827-transplanted athymic nude mice (Fig. 9D). Similarly, in H358 subcutaneous nude mice, the tumor volume and tumor weight were found to be reduced for CA and FE monotherapy, which was further attenuated for the two combinations with significant difference (Fig. 9E-G). There was no difference detected for the body weight among the mice from different groups (Fig. 9H). The data indicate that $\mathrm{CA}, \mathrm{FE}$ and, especially, their combination have inhibitory role in tumor growth in vivo, consistent with the results in vitro.

Combination of carnosic acid and fisetin impedes lung progression through apoptosis induction in vivo. In addition, p53, as previously reported, elevates DR gene transcription (28). Thus, p53 is important for TRAIL/DR-induced apoptosis in various tumors (29). To further confirm our hypothesis, IHC analysis was performed to calculate p53 levels in different tumor samples from mice under various conditions. As shown in Fig. 10A and B, CA and FE alone treatment could improve the number of p53 positive cells, being further enhanced for 

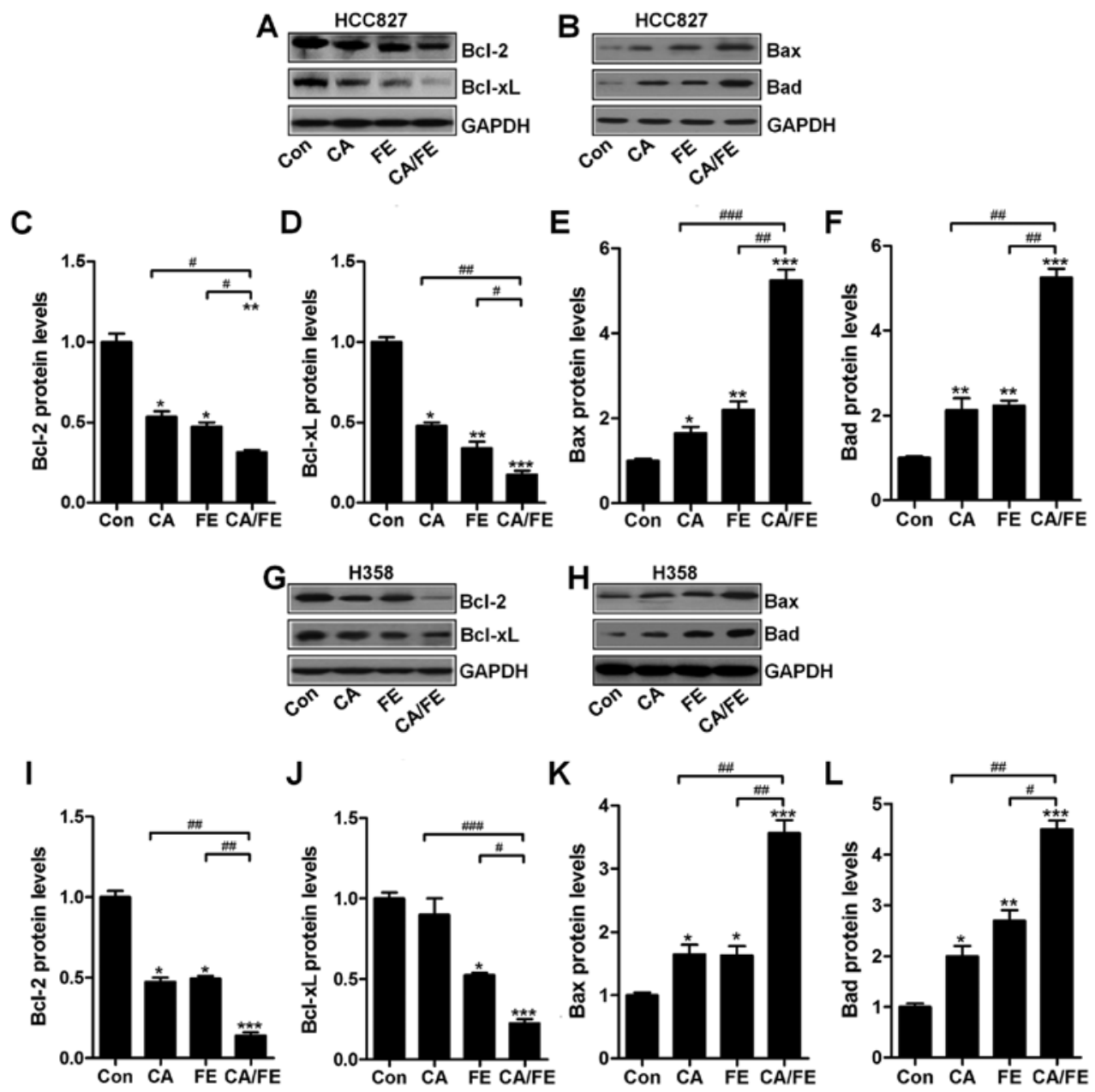

Figure 7. Carnosic acid and fisetin combination-induced apoptosis is associated with mitochondrial pathway. Expression of Bcl-2 family members, including (A) Bcl-2, Bcl-xl, and (B) Bax and Bad, in HCC827 cells under different experimental conditions were detected through western blot analysis. The representative images of immunoblot are displayed. The quantification of (C) Bcl-2, (D) Bcl-xl, (E) Bax, and (F) Bad based on western blot results in HCC827 cells is shown. Expression of Bcl-2 family members, including $(\mathrm{G}) \mathrm{Bcl}-2$, Bcl-xl and $(\mathrm{H}) \mathrm{Bax}$ and Bad, in HCC827 cells under different experimental conditions were detected through western blot analysis. The representative images of immunobot are displayed. The quantification of (I) Bcl-2, (J) Bcl-xl, (K) Bax and (L) Bad protein based on western blot results in $\mathrm{H} 358$ cells is shown. Values are means \pm SEM. ${ }^{*} \mathrm{P}<0.05,{ }^{* *} \mathrm{P}<0.01$ and ${ }^{* * * *} \mathrm{P}<0.001$ vs. Con group; ${ }^{\#} \mathrm{P}<0.05$, ${ }^{\# \#} \mathrm{P}<0.01$ and ${ }^{\# \# t} \mathrm{P}<0.001$.
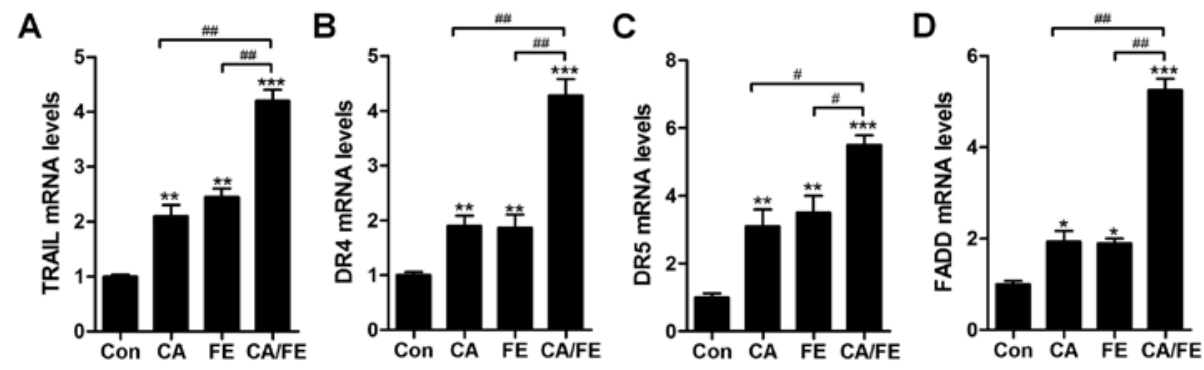

E

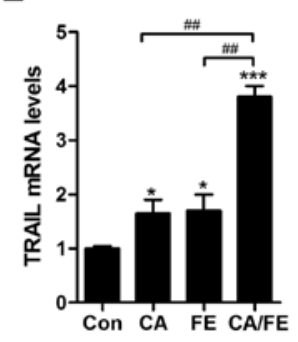

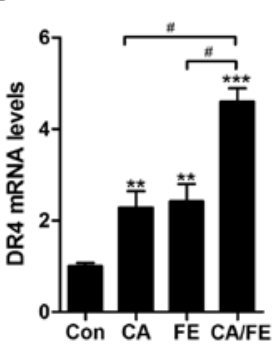
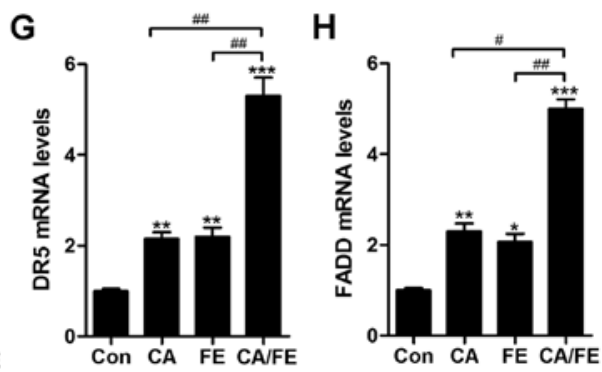

Figure 8. The effects of carnosic acid and fisetin combination suppressed lung cancer cells through TRAIL signaling pathway regulation. After different treatments of CA, FE and the two combinations for $24 \mathrm{~h}, \mathrm{RT}$-qPCR was carried out to determine mRNA levels of (A) TRAIL, (B) DR4, (C) DR5, (D) FADD in HCC827 cells. Also, in H358 cells under various conditions, (E) TRAIL, (F) DR4, (G) DR5 and (H) FADD mRNA levels were evaluated by RT-qPCR. Values are means \pm SEM. ${ }^{*} \mathrm{P}<0.05,{ }^{* *} \mathrm{P}<0.01$ and ${ }^{* * *} \mathrm{P}<0.001$ vs. Con group; ${ }^{\sharp} \mathrm{P}<0.05,{ }^{\# \#} \mathrm{P}<0.01$. 
A
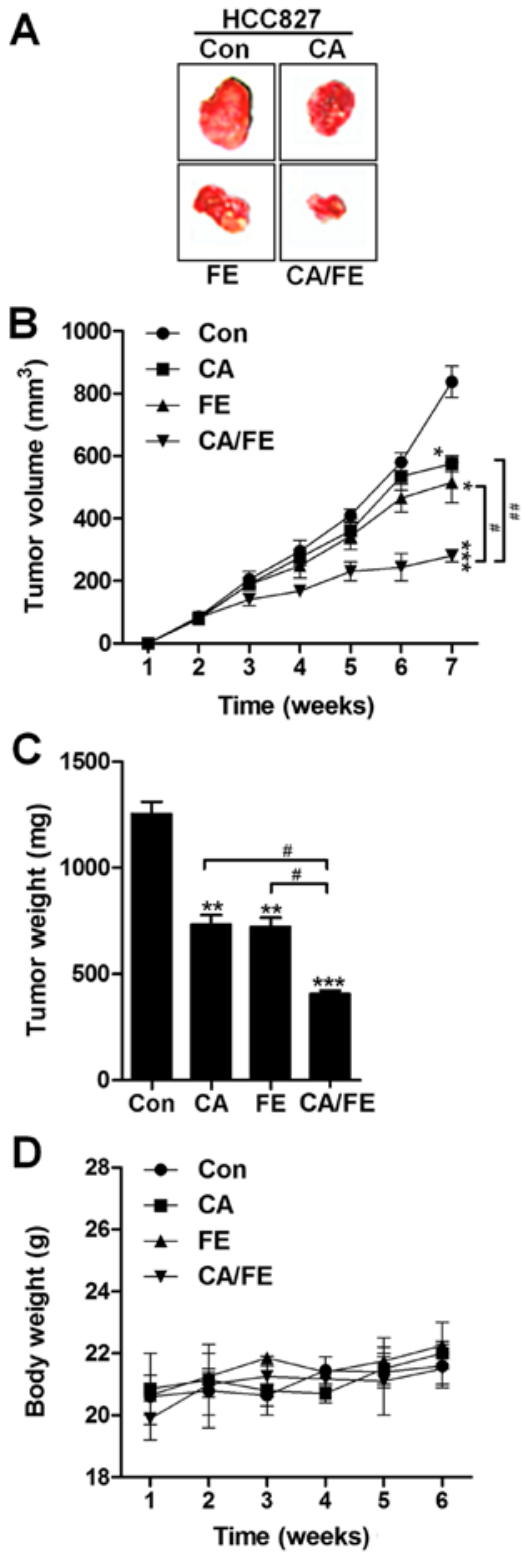

E
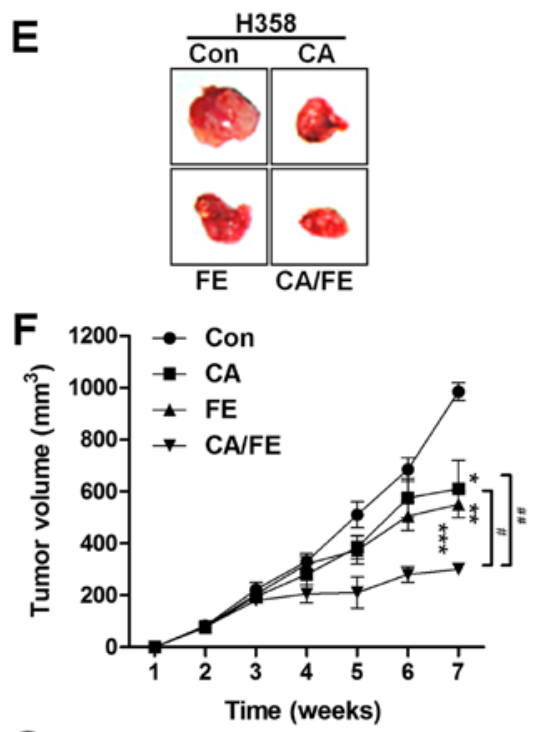

G

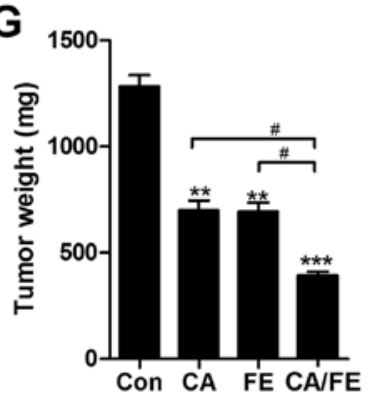

$\mathrm{H}$

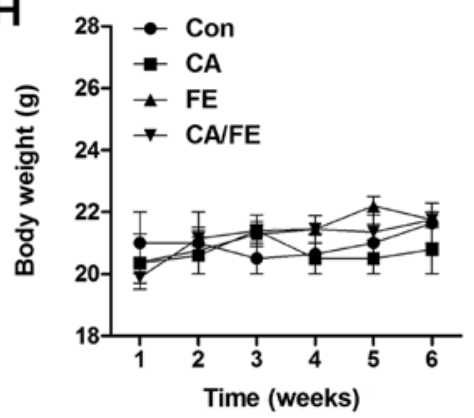

Figure 9. Carnosic acid and fisetin combination suppresses tumor growth in lung cancer xenograft models in vivo. The schematic is for CA and FE alone or the two combinations for HCC 827 and $\mathrm{H} 358$ subcutaneous tumors. After seven days, the animals were i.p. with CA ( $30 \mathrm{mg} / \mathrm{kg}), \mathrm{FE}(20 \mathrm{mg} / \mathrm{kg}) \mathrm{or} \mathrm{CA} / \mathrm{FE}$ $(30 / 20 \mathrm{mg} / \mathrm{kg})$ for a total of 7 weeks. Subsequently, the animals were sacrificed for the following studies. (A) The representative images of HCC827 tumor of mice from each group. (B) The HCC827 tumor volume was determined. (C) The HCC827 tumor weight was measured. (D) The body weight of mice with HCC827 cell injection was determined in the end of the present study. (E) The representative images of H358 tumor of mice from each group. (F) The H358 tumor volume was determined. (G) The $\mathrm{H} 358$ tumor weight was measured. (H) The body weight of mice with $\mathrm{H} 358$ cell injection was determined in the end of the study. Values are means \pm SEM. ${ }^{*} \mathrm{P}<0.05,{ }^{* *} \mathrm{P}<0.01$ and ${ }^{* * * *} \mathrm{P}<0.001$ vs. Con group; ${ }^{*} \mathrm{P}<0.05,{ }^{\# \#} \mathrm{P}<0.01$.

CA/FE in combination. In Fig. 10C and D, RT-qPCR analysis show lower mRNA levels of Bcl-2 and Bcl-xl in the presence of $\mathrm{CA}$ and FE than that observed in HCC827 tumor tissue samples treated by single therapy. In contrast, Bax and Bad were significantly upregulated after $\mathrm{CA}$ and $\mathrm{FE}$ alone, and were further elevated due to CA/FE co-treatment (Fig. 10E and F). Furthermore, RT-qPCR analysis suggested that in H358 tumor tissue samples, anti-apoptotic members of of $\mathrm{Bcl}-2$ and Bcl-xl were inhibited from gene levels in CA and FE single treatment, which were further reduced in the two-drug combinations with significant difference compared to the CA and FE single group (Fig. 10G and H). Bax and Bad mRNA levels in tumor samples from H358 subcutaneous mice were enhanced for $\mathrm{CA} / \mathrm{FE}$ in combination, which was comparable to the single-treated ones (Fig. 10I and J). The results illustrated that the $\mathrm{CA} / \mathrm{FE}$ in combination suppresses lung tumor growth through apoptosis induction in vivo, which is consistent with the results in vitro.

\section{Discussion}

Lung cancer is known as the leading cause contributing to death in human, and its incidence and mortality will be increasing worldwide. In addition, non-small cell lung cancer (NSCLC) is the most common type among different lung cancers $(30,31)$. In recent decades, although progress has been 

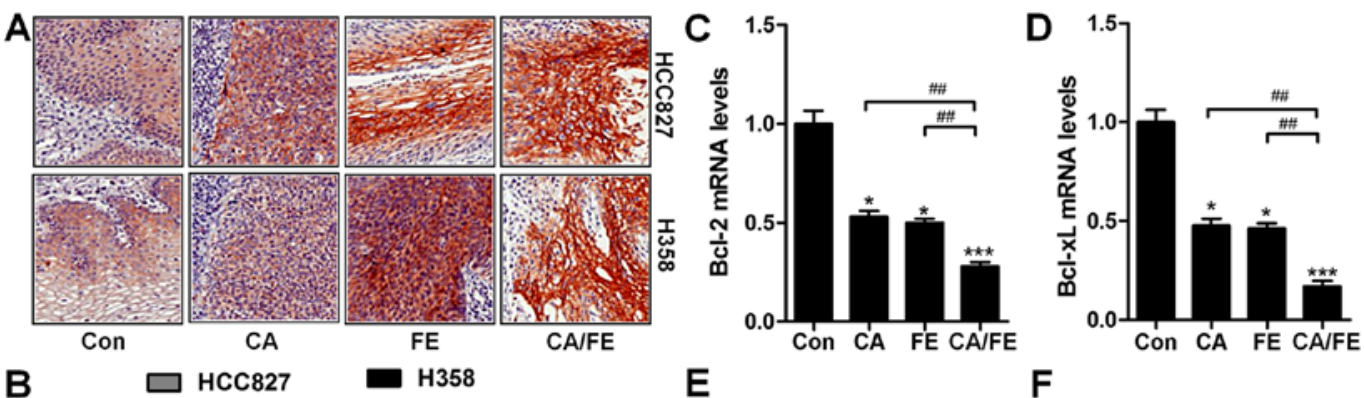

B

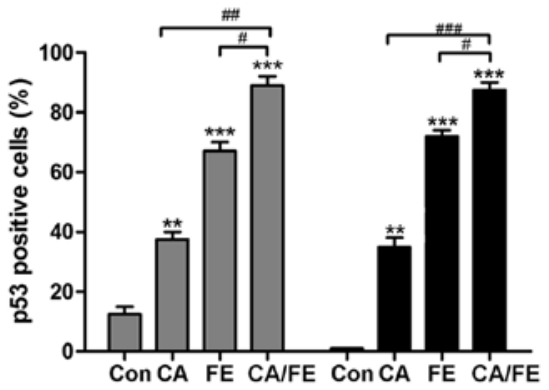

G

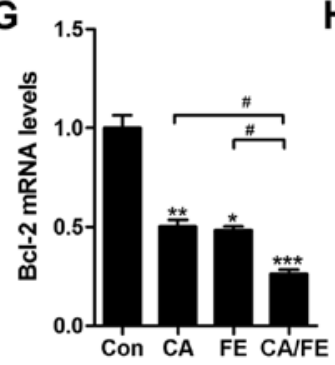

H

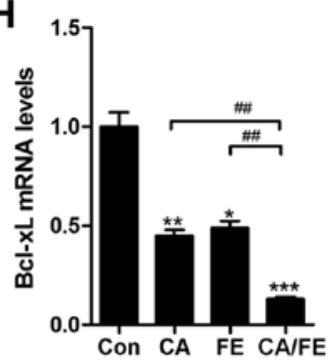

E
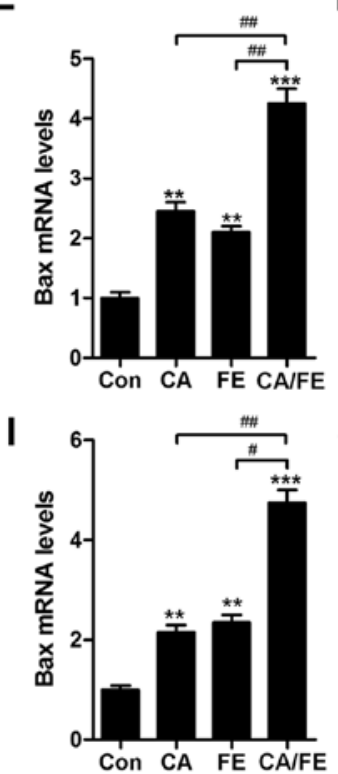

F
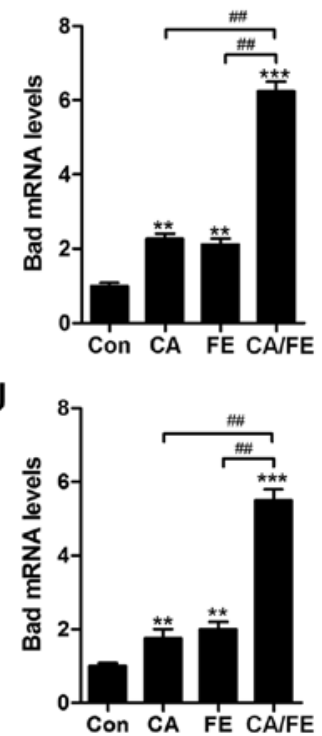

Figure 10. Combination of carnosic acid and fisetin impedes lung progression through apoptosis induction in vivo. (A) In HCC827 and H358 tumors, immunohistochemical (IHC) analysis was used to calculate the p53 levels. The representative images are displayed. (B) The quantification of positive cells of p53 was calculated. Total mRNA was extracted from HCC827 and H358 tumors from mice under different treatments for RT-qPCR assays. (C) Bcl-2, (D) Bcl-xl, (E) Bax and (F) Bad mRNA levels were examined in HCC827 tumor tissue samples. (G) Bcl-2, (H) Bcl-xl, (I) Bax and (J) Bad mRNA expression levels was determined in $\mathrm{H} 358$ tumor tissue samples. Values are means $\pm \mathrm{SEM} .{ }^{*} \mathrm{P}<0.05,{ }^{* *} \mathrm{P}<0.01$ and ${ }^{* * *} \mathrm{P}<0.001$ vs. Con group; ${ }^{\#} \mathrm{P}<0.05,{ }^{\# \#} \mathrm{P}<0.01$ and ${ }^{\# \# \#} \mathrm{P}<0.001$.

made in experimental as well as clinical oncology, the lung cancer prognosis is still far from satisfactory. Also, the 5-year survival rate is approxiamtely $15 \%$ (32). Therefore, finding effective therapeutic strategy and understanding the molecular mechanism of lung cancer for its progression is still urgently needed to find better treatments. Carnosic acid is an active component isolated from plants, which has been reported to suppress various human cancer progression, such as breast, gastric cancer and liver disease, through apoptosis induction and cell cycle arrest $(8,9)$. Fisetin is a naturally flavonoid, found in many vegetables and fruits, including cucumbers, onions, grapes, apples, persimmons and strawberries. The anti-oxidative, anti-inflammatory and neuro-protective activities of fisetin have been reported $(11,12,33)$. It has exerted anti-proliferative, pro-apoptotic and antitumorigenic activities. Also, combination treatment may improve life quality and prolong survival. Previous studies have reported that therapy in combination exhibited higher efficiency than those displayed with monotherapy in various tumors, such as gastric cancer (34). However, until now, little is known on whether carnosic acid combined to fisetin could be worthwhile to prevent lung cancer progression.

In the present study, carnosic acid and fisetin alone suppressed lung cancer HCC827 and H358 cell proliferation without cytotoxicity on normal lung cells (Figs. 1 and 2).
Significantly, carnosic acid and fisetin in combination showed stronger anticancer role in suppressing lung cancer cell proliferation. The present study provided the effects of carnosic acid and fisetin combination on lung cancer cell alteration. Detailed study here indicated that caspase-8, caspase-9, caspase-3, Bax, TRAIL, p53, DR4, DR5 and FADD were increased (Figs. 5 and 8), while Bcl-2 and Bcl-xl were decreased for carnosic acid and fisetin in combination (Fig. 7), indicating that these signaling pathways were involved in carnosic acid/fisetin-regulated lung cancer development. In addition, the combination of carnosic acid and fisetin in limiting lung cancer was further confirmed by in vivo study in nude mice that carnosic acid and fisetin multiple therapy suppressed tumor growth, which was more significant than carnosic acid and fisetin single therapy (Fig. 9). Furthermore, MTT assays showed no significant cell death after carnosic acid, fisetin and their combination treatment in normal lung cells from human (Fig. 1). Therefore, carnosic acid and fisetin combination might be a novel option for lung cancer treatment in future.

Here in the present study, we found that carnosic acid and fisetin alone treatments suppressed HCC827 and H358 cell proliferation. Compared to carnosic acid and fisetin single treatment, the two-combined therapy even in lower concentrations showed stronger inhibitory role in lung cancer cell proliferation, triggering considerable apoptosis. Caspases 
have been reported to play a significant role in cell apoptosis induction through TRAIL receptors and the mitochondrial signaling pathways via $\mathrm{Bcl}-2$ and $\mathrm{Bax}(35,36)$. In order to investigate the molecular mechanism by which carnosic acid and fisetin performed in lung cancer development suppression, the activation of caspase- 8 , caspase- 9 and caspase- 3 were detected through western blot analysis. The results indicated that carnosic acid and fisetin in combinationinduced cell apoptosis relied on caspase- 8 , caspase- 9 and caspase-3 activation (Fig. 5). Next, nuclear condensation was generated for caspase-3 activity, causing apoptosis in lung cancer cells (37). Caspase- 8 is of importance in mediating apoptosis via mitochondrial signaling pathway. The ratio of Bax:Bcl-2 is a key in apoptosis modulation via pro-apoptotic and anti-apoptotic members release $(38,39)$. Pro-apoptotic molecules inreasing, such as Bax and Bad, helps to produce apoptosis, while promotion of anti-apoptotic signals, including Bcl-2 and Bcl-xl, protect cancer cells from experiencing death $(40,41)$. In this study, carnosic acid and fisetin combinational treatment downregulated Bcl-2 and Bcl-xl expression levels, whereas Bax and Bad were upregulated significantly, upregulating the ratio of Bax:Bcl-2, causing apoptosis, which was consistent with TUNEL results in lung cancer cells (Figs. 4 and 7).

TRAIL, belonging to TNF superfamily, leads to rapid apoptosis through interactions with death receptors (DRs), which includ DR4 and DR5. TRAIL inhibits cancer cells preferentially over other normal cells, indicating its possible effects on anticancer treatment $(42,43)$. DR4 and DR5 activation accumulated Fas-associated death domain (FADD) and caspase-8, causing caspase-3 activity and apoptosis eventually $(44,45)$. The present study suggested that carnosic acid and fisetin in combination significantly upregulated TRAIL, DR4, DR5 and FADD mRNA levels. p53 activation was also apparently induced by carnosic acid and fisetin combined treatment (Fig. 8). The results obviously elucidated that carnosic acid and fisetin combinational treatment is dependent on TRAIL/caspase-related signaling pathway.

In conclusion, the results above indicated that carnosic acid and fisetin combination inhibited lung cancer progression in vitro and in vivo, which is related to TRAIL/caspase signaling pathway modulation, promoting lung cancer cell apoptosis without toxicity in normal cells. The results of the present study revealed that combination of carnosic acid and fisetin has potential therapeutic role in suppressing human lung cancer progression.

\section{References}

1. Zhang XY and Zhang P: Sensitization strategies in lung cancer (Review). Oncol Lett 12: 3669-3673, 2016.

2. Jemal A, Siegel R, Xu J and Ward E: Cancer statistics, 2010. CA Cancer J Clin 60: 277-300, 2010.

3. Siegel R, Ward E, Brawley O and Jemal A: Cancer statistics, 2011: The impact of eliminating socioeconomic and racial disparities on premature cancer deaths. CA Cancer J Clin 61: 212-236, 2011.

4. Alberg AJ, Ford JG and Samet JM; American College of Chest Physicians: Epidemiology of lung cancer: ACCP evidence-based clinical practice guidelines (2nd edition). Chest 132 (Suppl): 29S-55S, 2007.

5. Cui Y, Wang G, Li Y, Wang Y, Wang X and Bi H: Optical coherence tomography and histopathology of macular uveitis. Optom Vis Sci 91: 1335-1342, 2014.
6. Zou ZP, Qiang FY, Zhang T, Sun L, Jia T, Zhu XC and Xu H: Treatment of experimental autoimmune uveitis in rats with arsenic trioxide. Chin Ophthalmic Res 28: 306-310, 2010.

7. Mira A, Tanaka A, Tateyama Y, Kondo R and Shimizu K: Comparative biological study of roots, stems, leaves, and seeds of Angelica shikokiana Makino. J Ethnopharmacol 148: 980-987, 2013.

8. Cheung S and Tai J: Anti-proliferative and antioxidant properties of rosemary Rosmarinus officinalis. Oncol Rep 17: 1525-1531, 2007.

9. Steiner M, Priel I, Giat J, Levy J, Sharoni Y and Danilenko M: Carnosic acid inhibits proliferation and augments differentiation of human leukemic cells induced by 1,25-dihydroxyvitamin D3 and retinoic acid. Nutr Cancer 41: 135-144, 2001.

10. Murtaza I, Adhami VM, Hafeez BB, Saleem M and Mukhtar H: Fisetin, a natural flavonoid, targets chemoresistant human pancreatic cancer AsPC-1 cells through DR3-mediated inhibition of NF-kappaB. Int J Cancer 125: 2465-2473, 2009.

11. Li J, Cheng Y, Qu W, Sun Y, Wang Z, Wang H and Tian B: Fisetin, a dietary flavonoid, induces cell cycle arrest and apoptosis through activation of p53 and inhibition of NF-kappa B pathways in bladder cancer cells. Basic Clin Pharmacol Toxicol 108: 84-93, 2011.

12. Ying TH, Yang SF, Tsai SJ, Hsieh SC, Huang YC, Bau DT and Hsieh YH: Fisetin induces apoptosis in human cervical cancer HeLa cells through ERK1/2-mediated activation of caspase-8-/ caspase-3-dependent pathway. Arch Toxicol 86: 263-273, 2012.

13. Khan N, Asim M, Afaq F, Abu Zaid M and Mukhtar H: A novel dietary flavonoid fisetin inhibits androgen receptor signaling and tumor growth in athymic nude mice. Cancer Res 68: 8555-8563, 2008.

14. Szliszka E, Helewski KJ, Mizgala E and Krol W: The dietary flavonol fisetin enhances the apoptosis-inducing potential of TRAIL in prostate cancer cells. Int J Oncol 39: 771-779, 2011.

15. Yang PM, Tseng HH, Peng CW, Chen WS and Chiu SJ: Dietary flavonoid fisetin targets caspase-3-deficient human breast cancer MCF-7 cells by induction of caspase-7-associated apoptosis and inhibition of autophagy. Int J Oncol 40: 469-478, 2012.

16. Liang J, Deng X, Wu FS and Tang YF: Transcriptomic and proteomic analysis of human hepatic stellate cells treated with natural taurine. Mol Med Rep 7: 1442-1452, 2013.

17. Li DW, Li JH, Wang YD and Li GR: Atorvastatin protects endothelial colony-forming cells against $\mathrm{H}_{2} \mathrm{O}_{2}$-induced oxidative damage by regulating the expression of annexin A2. Mol Med Rep 12: 7941-7948, 2015.

18. Cai JJ, Qi ZX, Chen LC, Yao Y, Gong Y and Mao Y: miR-124 suppresses the migration and invasion of glioma cells in vitro via Capn4. Oncol Rep 35: 284-290, 2016.

19. Joshi A, Allen R, Kroetz D, Schaller M, Dalton J, Kunkel S and Gallagher K: Histone methyltransferase, Setdb2, regulates wound healing in a diet-induced obesity model of diabetes (IRM9P. 601). J Immunol 194 (Suppl 1): 130.10, 2015.

20. Lyons AB, Blake SJ and Doherty KV: Flow cytometric analysis of cell division by dilution of CFSE and related dyes. Curr Protoc Cytom Chapter 9: 11, 2013.

21. Polikepahad S, Knight JM, Naghavi AO, Oplt T, Creighton CJ, Shaw C, Benham AL, Kim J, Soibam B, Harris RA, et al: Proinflammatory role for let-7 microRNAS in experimental asthma. J Biol Chem 285: 30139-30149, 2010.

22. Cagin YF, Parlakpinar H, Vardi N, Polat A, Atayan Y, Erdogan MA and Tanbek K: Effects of dexpanthenol on acetic acid-induced colitis in rats. Exp Ther Med 12: 2958-2964, 2016.

23. Trussardi-Regnier A, Lavenus S, Gorisse MC and Dufer J: Thalidomide alters nuclear architecture without ABCB1 gene modulation in drug-resistant myeloma cells. Int J Oncol 35: 641-647, 2009.

24. Schultz DR and Harrington WJ Jr: Apoptosis: Programmed cell death at a molecular level. Semin Arthritis Rheum 32: 345-369, 2003.

25. Li P, Nijhawan D, Budihardjo I, Srinivasula SM, Ahmad M, Alnemri ES and Wang X: Cytochrome c and dATP-dependent formation of Apaf-1/caspase-9 complex initiates an apoptotic protease cascade. Cell 91: 479-489, 1997.

26. Ashkenazi A, Holland P and Eckhardt SG: Ligand-based targeting of apoptosis in cancer: The potential of recombinant human apoptosis ligand $2 /$ tumor necrosis factor-related apoptosis-inducing ligand (rhApo2L/TRAIL). J Clin Oncol 26: 3621-3630, 2008. 
27. Pan Y, Xu R, Peach M, Huang CP, Branstetter D, Novotny W, Herbst RS, Eckhardt SG and Holland PM: Evaluation of pharmacodynamic biomarkers in a Phase 1a trial of dulanermin (rhApo2L/TRAIL) in patients with advanced tumours. Br J Cancer 105: 1830-1838, 2011.

28. Wiezorek J, Holland P and Graves J: Death receptor agonists as a targeted therapy for cancer. Clin Cancer Res 16: 1701-1708, 2010.

29. Dimberg LY, Anderson CK, Camidge R, Behbakht K, Thorburn A and Ford HL: On the TRAIL to successful cancer therapy? Predicting and counteracting resistance against TRAIL-based therapeutics. Oncogene 32: 1341-1350, 2013.

30. Dela Cruz CS, Tanoue LT and Matthay RA: Lung cancer: Epidemiology, etiology, and prevention. Clin Chest Med 32: 605-644, 2011.

31. Ganti AK, Siedlik E, Marr AS, Loberiza FR Jr and Kessinger A Predictive ability of Charlson comorbidity index on outcomes from lung cancer. Am J Clin Oncol 34: 593-596, 2011.

32. Yao J, Wang YW, Fang BB, Zhang SJ and Cheng BL: piR-651 and its function in 95-D lung cancer cells. Biomed Rep 4: 546-550, 2016.

33. Hou DX, Fukuda M, Johnson JA, Miyamori K, Ushikai M and Fujii M: Fisetin induces transcription of NADPH:quinone oxidoreductase gene through an antioxidant responsive elementinvolved activation. Int J Oncol 18: 1175-1179, 2001.

34. Daliani DD, Tannir NM, Papandreou CN, Wang X, Swisher S, Wood CG, Swanson DA, Logothetis CJ and Jonasch E: Prospective assessment of systemic therapy followed by surgical removal of metastases in selected patients with renal cell carcinoma. BJU Int 104: 456-460, 2009.

35. Zhang L and Fang B: Mechanisms of resistance to TRAILinduced apoptosis in cancer. Cancer Gene Ther 12: 228-237, 2005.

36. Jin Z, McDonald ER III, Dicker DT and El-Deiry WS: Deficient tumor necrosis factor-related apoptosis-inducing ligand (TRAIL) death receptor transport to the cell surface in human colon cancer cells selected for resistance to TRAIL-induced apoptosis. J Biol Chem 279: 35829-35839, 2004.
37. Kim HS, Lee JW, Soung YH, Park WS, Kim SY, Lee JH, Park JY, Cho YG, Kim CJ, Jeong SW, et al: Inactivating mutations of caspase- 8 gene in colorectal carcinomas. Gastroenterology 125 : 708-715, 2003.

38. Cummins JM, Kohli M, Rago C, Kinzler KW, Vogelstein B and Bunz F: X-linked inhibitor of apoptosis protein (XIAP) is a nonredundant modulator of tumor necrosis factor-related apoptosis-inducing ligand (TRAIL)-mediated apoptosis in human cancer cells. Cancer Res 64: 3006-3008, 2004

39. Zhang S, Ong CN and Shen HM: Involvement of proapoptotic Bcl-2 family members in parthenolide-induced mitochondrial dysfunction and apoptosis. Cancer Lett 211: 175-188, 2004.

40. Kim SL, Trang KT, Kim SH, Kim IH, Lee SO, Lee ST, Kim DG and Kim SW: Parthenolide suppresses tumor growth in a xenograft model of colorectal cancer cells by inducing mitochondrial dysfunction and apoptosis. Int J Oncol 41: 1547-1553, 2012.

41. Carlisi D, D'Anneo A, Angileri L, Lauricella M, Emanuele S, Santulli A, Vento R and Tesoriere G: Parthenolide sensitizes hepatocellular carcinoma cells to TRAIL by inducing the expression of death receptors through inhibition of STAT3 activation. J Cell Physiol 226: 1632-1641, 2011.

42. Vasilevskaya IA and O'Dwyer PJ: 17-Allylamino-17demethoxygeldanamycin overcomes TRAIL resistance in colon cancer cell lines. Biochem Pharmacol 70: 580-589, 2005.

43. Galligan L, Longley DB, McEwan M, Wilson TR, McLaughlin K and Johnston PG: Chemotherapy and TRAIL-mediated colon cancer cell death: The roles of p53, TRAIL receptors, and c-FLIP. Mol Cancer Ther 4: 2026-2036, 2005.

44. Pennarun B, Meijer A, de Vries EG, Kleibeuker JH, Kruyt F and de Jong S: Playing the DISC: Turning on TRAIL death receptormediated apoptosis in cancer. Biochim Biophys Acta 1805: $123-140,2010$

45. Jung YH, Heo J, Lee YJ, Kwon TK and Kim YH: Quercetin enhances TRAIL-induced apoptosis in prostate cancer cells via increased protein stability of death receptor 5. Life Sci 86: 351-357, 2010. 